\title{
Levothyroxine Dose Adjustment to Optimise Therapy Throughout a Patient's Lifetime
}

\author{
Leonidas H. Duntas · Jacqueline Jonklaas
}

Received: August 16, 2019 / Published online: September 4, 2019

(C) The Author(s) 2019

\begin{abstract}
Levothyroxine is the standard therapy for patients with hypothyroidism, a condition that affects up to $5 \%$ of people worldwide. While levothyroxine therapy has substantially improved the lives of millions of hypothyroid patients since its introduction in 1949, the complexity of maintaining biochemical and clinical euthyroidism in patients undergoing treatment with levothyroxine cannot be underestimated. Initial dosing of levothyroxine can vary greatly and may be based on the amount of residual thyroid function retained by the patient, the body weight or lean body mass of the patient, and thyroid-stimulating hormone levels. As levothyroxine is usually administered over a patient's lifetime, physiological changes throughout life will affect the dose of levothyroxine required to maintain euthyroidism. Furthermore, dose adjustments
\end{abstract}

Enhanced Digital Features To view enhanced digital features for this article go to https://doi.org/10.6084/ m9.figshare.9706403.

\footnotetext{
L. H. Duntas ( $₫)$

Unit of Endocrinology, Diabetes, and Metabolism, Thyroid Section, Evgenidion Hospital, Athens, Greece

e-mail: ledunt@otenet.gr

J. Jonklaas

Division of Endocrinology, Georgetown University,

Washington, DC, USA
}

may need to be made in patients with concomitant medical conditions, in patients taking certain medications, as well as in elderly patients. Patients who have undergone any weight or hormonal changes may require dose adjustments, and the majority of pregnant women require increased doses of levothyroxine. Optimal treatment of hypothyroidism requires a partnership between patient and physician. The physician is tasked with vigilant appraisal of the patient's status based on a thorough clinical and laboratory assessment and appropriate adjustment of their levothyroxine therapy. The patient in turn is tasked with medication adherence and reporting of symptomatology and any changes in their medical situation. The goal is consistent maintenance of euthyroidism, without the patient experiencing the adverse events and negative health consequences of under- or overtreatment.

Funding Merck.

Plain Language Summary Plain language summary available for this article.

Keywords: Dose adjustment; Endocrinology; Hypothyroidism; Levothyroxine; Lifespan; Medical conditions; Medications 


\section{PLAIN LANGUAGE SUMMARY}

Hypothyroidism, a reduction in thyroid hormone levels, is one of the most common diseases worldwide. The medication most used to treat hypothyroidism is levothyroxine, a compound that acts as a replacement for a person's thyroid hormone. People with hypothyroidism will often need to take levothyroxine for a long time, typically for the rest of their life, so it is important that their treatment is monitored closely and the dose is adjusted for the best effect as needed. As a person progresses through life, their dose may need to be adjusted because other diseases or medications can affect the dose needed for effective treatment. Pregnancy or weight gain can also affect the dose of levothyroxine needed by the patient, so patients and physicians need to work in partnership to ensure that the treatment is working as well as it can. The goal of this partnership is to maintain normal thyroid hormone levels without the patient experiencing any side effects or negative health consequences of taking too much or too little levothyroxine.

\section{INTRODUCTION}

Thyroxine was isolated on Christmas Day 1914 by Kendall. Its chemical structure was determined in 1926 by Harington, and it was synthesised in 1927 by Harington and Barger [1, 2]. The acidity of the thyroxine molecule, which caused diminished absorption resulting in low bioavailability, was an unresolved problem for more than 20 years following its discovery [3]. In 1949 , a commercial product containing synthesised sodium thyroxine was launched in the USA and some years later in Europe, signalling a new era in the treatment of hypothyroidism, which had advanced from partially purified extracts of bovine thyroid gland and desiccated thyroid extracts from sheep and pigs to fully synthesised thyroxine $[4,5]$. The manufacture of sodium thyroxine (levothyroxine) thus resulted in a major pharmacological achievement in endocrinology, giving a more stable and effective thyroid hormone compound that, over the last few decades, has considerably improved the lives of millions of patients with various forms of hypothyroidism.

The objective of this review is to provide an overview of (1) when administration of levothyroxine is necessary, (2) initial dosing and subsequent adjustment of levothyroxine, (3) the importance of avoiding under- and overtreatment with levothyroxine, (4) the need for levothyroxine dose adjustment through various phases of life, (5) medical conditions and medications necessitating levothyroxine dose adjustments, as well as (6) controversies about treatment with products other than levothyroxine. Diligent monitoring of patients taking levothyroxine and regular dose adjustment to achieve optimised treatment and avoidance of adverse events are particularly emphasised.

\section{METHODS}

A search of the literature was conducted using the PubMed and CENTRAL (Cochrane) databases. Keywords relating to levothyroxine, hypothyroidism, treatment, levothyroxine dose adjustments, levothyroxine and concomitant conditions, levothyroxine and concomitant medications, and combined treatment with levothyroxine and liothyronine versus levothyroxine were searched. Only reviews and articles providing clinical data, particularly the most recent, were considered. Potential articles of interest were identified by title and abstract, and citation lists of articles of interest were used to identify additional literature. This article is based on previously conducted studies and does not contain any studies with animals performed by any of the authors. Some of the studies cited include analyses, or studies with human participants, performed by the authors and completed prior to the initiation of this manuscript.

\section{WHEN LEVOTHYROXINE ADMINISTRATION IS A NECESSITY}

Thyroxine is secreted by the thyrocytes and is the main thyroid hormone in the circulation. Thyroxine is actively transported to the various organs where it is converted to triiodothyronine 
by the activity of the deiodinases [6]. Triiodothyronine, the active form of thyroid hormone, is secreted in small amounts by the thyroid but is mainly generated via extrathyroidal conversion of the prohormone thyroxine. Hypothyroidism is a common endocrine disease that requires timely and lifelong treatment since, if left untreated, it can contribute to hypertension, dyslipidaemia, and heart failure and induce reversible dementia and infertility, as well as neurosensory, musculoskeletal, and gastrointestinal symptoms [7]. There is currently no other treatment for hypothyroidism, other than providing thyroid hormone replacement. Due to its long half-life of about 7 days, in patients in the clinically euthyroid state, levothyroxine is the preferred first-line treatment for primary hypothyroidism and has been the most commonly prescribed treatment since the 1980s [8].

\section{INITIAL DOSING AND DOSE ADJUSTMENT OF LEVOTHYROXINE DURING THERAPY}

\section{Initial Dosing}

The levothyroxine dose initially required by a patient depends primarily on three factors: the amount of residual thyroid function retained by the patient, the body weight or lean body mass of the patient, and the target thyrotropin or thyroid-stimulating hormone (TSH) level to be achieved during therapy [8]. Additional factors such as patient age, patient sex, and menopausal status may have an influence that is generally of lesser magnitude. Other physiological factors such as pregnancy and gastrointestinal functioning may be important factors in specific patients or at specific times [8].

When commencing levothyroxine therapy, initial dose requirements can vary greatly from small doses such as $25-50 \mu \mathrm{g}$ in an individual with mild or subclinical disease, where the therapy may be supplementing endogenous function, to larger doses of $88-175 \mu \mathrm{g}$ in cases of patients with negligible endogenous thyroid function. In keeping with this concept, the initial dose of levothyroxine in patients presenting to a clinic with primary hypothyroidism can be predicted by the patient's TSH value prior to initiation of treatment [9]. In the case of surgically athyreotic patients, the dose of levothyroxine required may be slightly higher than in those with autoimmune thyroid disease [8], presumably reflecting some retained thyroid hormone production in those with autoimmune thyroid disease. An example of the dose requirement in those with Hashimoto's thyroiditis without residual function and post-surgical hypothyroidism is approximately $1.6 \mu \mathrm{g} /$ $\mathrm{kg}$ [8]. The dose of levothyroxine required by a patient following thyroidectomy can be predicted by either body weight or body mass index (BMI) [10-12]. Body weight, BMI, ideal body weight, and lean body mass can all predict the initial dose requirement, with the latter three parameters providing the more accurate estimates [10, 13]. Various formulae have been proposed to calculate dose requirement. These range from simple formulae based only on body weight or BMI to more complex formulae that also incorporate other factors such as patient sex $[10,14]$. Generally, both a TSH-based estimate and a body weight-based estimate yield similar initial estimates of dose requirement (Fig. 1). With respect to age, for patients who are elderly, have concomitant cardiac disease, or may have had long-standing untreated hypothyroidism, it is wise to initiate levothyroxine therapy with smaller doses such as 25-50 $\mu \mathrm{g}$ levothyroxine and incrementally increase the dose to full replacement to avoid precipitating cardiac ischaemia [8].

\section{Dose Adjustment}

Regardless of the method used to estimate the initial levothyroxine dose requirement, dose adjustment is frequently required. This may be due to multiple factors including limitations in the dose requirement predictions, inter-patient variation, levothyroxine absorption, or effects of concomitant medical conditions or medications [8]. Given the half-life of levothyroxine (approximately 1 week), reassessment of thyroid status by serum TSH levels, and free 


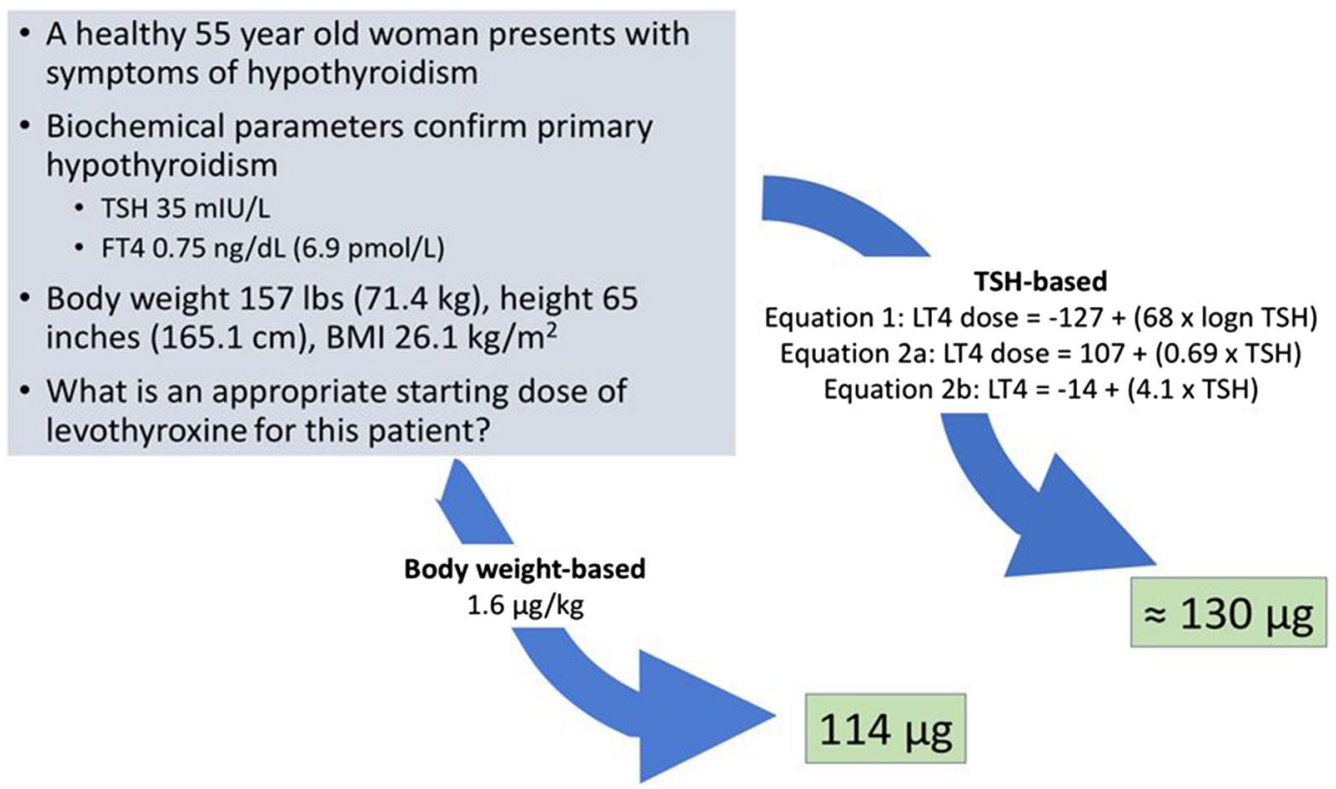

Fig. 1 Example of body weight- and thyroid-stimulating hormone-based levothyroxine initial dose estimates. $B M I$ body mass index, FT4 free thyroxine, LT4 levothyroxine, TSH thyroid-stimulating hormone

thyroxine levels if desired, is indicated after 6 weeks of therapy when the pharmacokinetic steady state is reached. If the TSH is not at the desired goal, the levothyroxine dose can be adjusted up or down. TSH values that are slightly out of range may be corrected by a single dose increment or decrement, such as increasing from 100 to $112 \mu \mathrm{g}$ or decreasing from 175 to $150 \mu \mathrm{g}$. TSH values that are considerably out of range may require larger percentage changes. Levothyroxine absorption is maximised, at about $75 \%$ of the administered dose, when it is ingested upon an empty stomach [8]. Therefore, if levothyroxine is taken at other times of the day for convenience, the dose requirement may be greater and potentially more variable [15]. Once the desired TSH value has been achieved, it could potentially be reconfirmed by laboratory testing in 3-6 months, and then checked on an annual basis thereafter. A stable TSH while receiving levothyroxine therapy was inversely associated with the magnitude of the levothyroxine dose in one study, perhaps suggesting that residual thyroid function provided some buffer against TSH variations in those who required smaller levothyroxine doses [16].
Simple regimens that involve the same dose taken daily are ideal with respect to ease of adherence, although sometimes regimens that involve alternating doses or use of half tablets are needed to achieve the desired TSH value. A study comparing TSH values achieved with use of whole levothyroxine tablets versus split tablets showed comparable TSH values [17], but nevertheless any unnecessary complications to a regimen that patients will be following for a lifetime need to be minimised. There do seem to be a variety of costs, such as utilisation of health care resources, and comorbidities, such as depression and dyslipidaemia, associated with non-adherence to levothyroxine therapy, as demonstrated in a study funded by levothyroxine manufacturers [18]. Non-adherence to levothyroxine is generally associated with an elevated TSH. However, if missed doses are not reported by the patient, levothyroxine dose increases can lead to a low TSH if therapy is later adhered to. If problems with non-adherence and an elevated TSH are not corrected by education or treatment of contributing conditions such as depression or psychiatric disorders, possible solutions to improve adherence include observed weekly oral levothyroxine 
- A 67 year old woman with hypothyroidism notes persistent symptoms of hypothyroidism

- She states she takes her $100 \mu \mathrm{g}$ LT4 and her cholecalciferol regularly

- Biochemical evaluation:

- $\mathrm{TSH} 47 \mathrm{mIU} / \mathrm{L}$

- FT4 $1.2 \mathrm{ng} / \mathrm{dL}$

- $25(\mathrm{OH})$ vitamin D $5 \mathrm{ng} / \mathrm{dL}$

- What is explanation and approach to therapy in this patient?

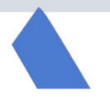

Repeated LT4 dose adjustments, discussion with patient and referral to psychiatrist for depression (patient's spouse recently deceased)

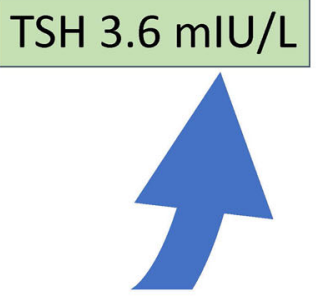

Twice weekly observed oral therapy instituted with $400 \mu \mathrm{g}$ and $300 \mu \mathrm{g}$ LT4 doses on Monday and Thursday

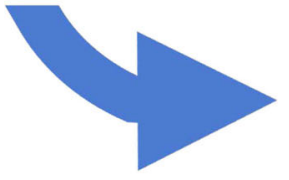

Serial TSH values: $0.01,75,0.2,39 \mathrm{mIU} / \mathrm{L}$ Serial $25(\mathrm{OH})$ vitamin $D$ values $120,7,102,9 \mathrm{ng} / \mathrm{dL}$ Patient later admits to "forgetting" her LT4 and taking extra make-up doses prior to appointments

Fig. 2 Example of how to address non-adherence to levothyroxine associated with elevated thyroid-stimulating hormone levels. $25(\mathrm{OH})$ vitamin $D$ 25-hydroxy vitamin

therapy (Fig. 2) [19, 20] or weekly or twice weekly parenteral administration (such as intravenous [21], subcutaneous [22], or intramuscular administration of levothyroxine [23]).

\section{AVOIDANCE OF OVER- AND UNDER-DOSING WITH LEVOTHYROXINE}

Generally, hypothyroidism may be effectively treated via a constant daily dose of levothyroxine, and, for the majority of confirmed aetiologies, this needs to be lifelong. However, in this setting, there appear to be many cases of both levothyroxine over- and under-dosing and it may be that frequent adjustments of a dose are necessary. These adjustments need to be handled with caution and take into account the many contributing factors, as multiple levothyroxine dose adjustments evidently result in a greater burden on healthcare resources [24]. This means that it is necessary for clinicians to determine which patients are truly in need of dose adjustment. Even more importantly, accumulating evidence suggests that many
D, FT4 free thyroxine, LT4 levothyroxine, TSH thyroidstimulating hormone

patients, for whom the indication for levothyroxine initiation is not adequately established and the diagnosis is not well documented, are remaining on levothyroxine therapy for longer than necessary. A prospective clinical cohort follow-up study illustrated this by showing that, among 291 patients (84\% females) on levothyroxine replacement therapy without a solid diagnosis of hypothyroidism and in whom the treatment was paused, 114 developed hypothyroidism, while 177 participants remained euthyroid. The latter results clearly point to a significant overuse of levothyroxine therapy [25].

Overtreatment should particularly be avoided in the elderly. A study seeking to determine whether levothyroxine pharmacokinetics are affected by age and weight did not identify any influence of age on the levothyroxine dose requirement, though it was determined that weight may mediate age-related changes in levothyroxine pharmacokinetics [26]. In addition, transient changes (e.g., illness), inter- and intra-individual differences in thyroid parameters, or ethnic variations may modify the treatment target, thus rendering advisable a tailored 
assessment of thyroid function. Use of thyroid extract, rather than levothyroxine, may be associated with overtreatment. In a study of 174 reports of adverse events occurring in patients taking thyroid hormone extract, 91 of these reports were accompanied by changes in TSH values and, of these, 62 patients $(68 \%)$ had developed new symptoms associated with TSH changes, with most (65\%) having symptoms consistent with thyrotoxicosis [27].

In a recent case report the authors describe two female patients with Takotsubo cardiomyopathy associated with levothyroxine over-replacement, clearly underlining the necessity to adjust the dose of levothyroxine, particularly in patients with cardiovascular risks, so as to avoid the deleterious effects of iatrogenic hyperthyroidism [28]. Another point to be considered in overzealously treated patients is the high risk of accelerated bone loss, predominantly in postmenopausal women, as well as the risk of osteoporosis and vertebral fractures [29]. Concerning under-dosage, while overtreatment was not associated with impairment of health-related quality of life (HRQoL), patients who are undertreated had worse HRQoL than overtreated patients, especially regarding physical and emotional aspects, independently of the degree of hypothyroidism [30]. Given that hypothyroidism undertreatment is associated with poor patient HRQoL, it is clear that levothyroxine therapy must be sufficient to maintain serum TSH within the reference range. Age-dependent interpretation of TSH values (extending from neonates to the very old), with appropriate consideration of circadian fluctuations, body weight, gastrointestinal diseases and malabsorption, comorbidity, and possibly pituitary insufficiency or thyroid hormone resistance, is thus crucial for optimal levothyroxine dosage.

Another factor that can be associated with under- or overtreatment with levothyroxine is switching between different preparations. Despite the availability of stable compounds of levothyroxine, over the past few decades, problems have repeatedly emerged concerning potency, which, according to specifications issued by the US Food and Drug Administration in 2007 , should not exceed $10 \%$ difference from the stated dose [31]. Furthermore, bioequivalence testing allows the $90 \%$ confidence interval of the difference in the areas under the curve and difference of maximum concentrations of serum T4 derived during pharmacokinetic testing to fall within $80-125 \%$ of that of a reference product [8] or the more stringent criteria of $90-111 \%$. It is well known that dose differences falling within this range result in clinically relevant dissimilarities in safety and effectiveness. In addition, any method of analysing bioequivalence data that does not take into account endogenous thyroxine concentrations will confound accurate quantitation and interpretation of levothyroxine bioavailability [32]. Hence, even products that meet the criteria for bioequivalence could well expose patients to the development of iatrogenic hyperthyroidism or hypothyroidism. While levothyroxine has a narrow therapeutic index [33], defined as having a narrow window between effective doses and those at which they produce adverse events, as well as a potential variance in the therapeutic efficacy among various levothyroxine preparations, there is at present no viable alternative to this treatment.

In summary, it is necessary in all cases to periodically verify the need for dose adjustment and/or continuation of treatment. If there is a suspicion for levothyroxine treatment having been prescribed unnecessarily, this can be investigated via a test period incorporating 6- to 8 -week therapy discontinuation, followed by TSH testing.

\section{FACTORS POTENTIALLY CONTRIBUTING TO THE NEED FOR LEVOTHYROXINE DOSE ADJUSTMENTS THROUGHOUT A PATIENT'S LIFE SPAN}

There are many factors encountered by patients across their life span that may be associated with an altered levothyroxine requirement. Newborns, children, and adolescents typically require higher levothyroxine doses than adults [8]. Examples of factors affecting the levothyroxine dose requirements of adults include 
pregnancy, weight changes, hormonal changes, and ageing.

\section{Pregnancy}

The dramatic increase in levothyroxine dose requirements associated with pregnancy, and the subsequent decrease in requirement postpartum are perhaps the best documented alterations in levothyroxine requirement [34]. The reason for the increased requirement is the need for an increased total body thyroxine pool associated with increased thyroxine-binding globulin concentrations and increased plasma volume. Increased levothyroxine doses are required in approximately $50-85 \%$ of pregnant women, and the need for an increase occurs early in the first trimester. Requirements tend to stabilise as the patient progresses into the second and third trimester, with few changes generally being required in the third trimester. The percentage increase in levothyroxine dose needed can be as high as $30-50 \%$ and is highest when the cause of the hypothyroidism is a thyroidectomy or ablation of the thyroid gland [35]. Achieving a serum TSH $<1.2 \mathrm{mIU} / 1$ preconception seems to reduce the percentage of patients requiring a dose increase [36]. Studies show that serum TSH can be maintained at goal during pregnancy by either increasing the levothyroxine dose by $29 \%$ by increasing from 7 to 9 tablets of levothyroxine weekly when conception is confirmed [37] or ongoing titration based on serum TSH [38]. The latter method had the advantage of resulting in fewer patients having a suppressed TSH during pregnancy [38]. Women undergoing in vitro fertilisation have similar needs for increased levothyroxine dosages, with $83 \%$ of women requiring an increase and the average increase being 33\% [39].

\section{Weight Changes and Hormonal Changes}

As mentioned above, levothyroxine dose requirements are affected by body weight, ideal body weight, and lean body mass, with dose requirements increasing as these parameters increase [8, 13, 40]. However, if actual body weight is used to calculate the levothyroxine requirement in obese individuals, the dose may be overestimated, with ideal body weight being a better predictor [40]. Moreover, the studies regarding levothyroxine requirement in obese individuals often yield differing results of either increased or decreased requirements, possibly because of competing effects of the increased body weight and the impaired absorption and altered levothyroxine kinetics that may be seen with obesity [41]. Different results have also been reported regarding the altered levothyroxine requirement associated with the weight loss seen after bariatric surgery. Most studies show that such weight loss is associated with a reduced levothyroxine requirement [42], possibly due to both the reduced weight and improved absorption. However, bariatric procedures involving jejunoileal bypass may be associated with an increased levothyroxine requirement because of reduced, as opposed to improved, levothyroxine absorption [43]. In cases where levothyroxine absorption is impaired after bariatric surgery, use of liquid levothyroxine may improve absorption [44].

With respect to hormonal changes, premenopausal women may require higher levothyroxine doses than postmenopausal women [40, 45, 46]. Conversely, oestrogen therapy is associated with a need for higher doses of levothyroxine to maintain the same serum TSH [47].

\section{Ageing}

Several studies have shown that the levothyroxine dose requirement is decreased in older individuals $[8,48,49]$. However, a recent study suggests that this decreased requirement may be mediated by the changes in weight that may accompany ageing [26]. Other important considerations regarding levothyroxine doses in older individuals include bearing age-adjusted TSH reference ranges in mind [50] and avoiding over-replacement that might potentially exacerbate other medical conditions [8]. Both of these considerations would lead to targeting of higher TSH values in older individuals (Fig. 3). 


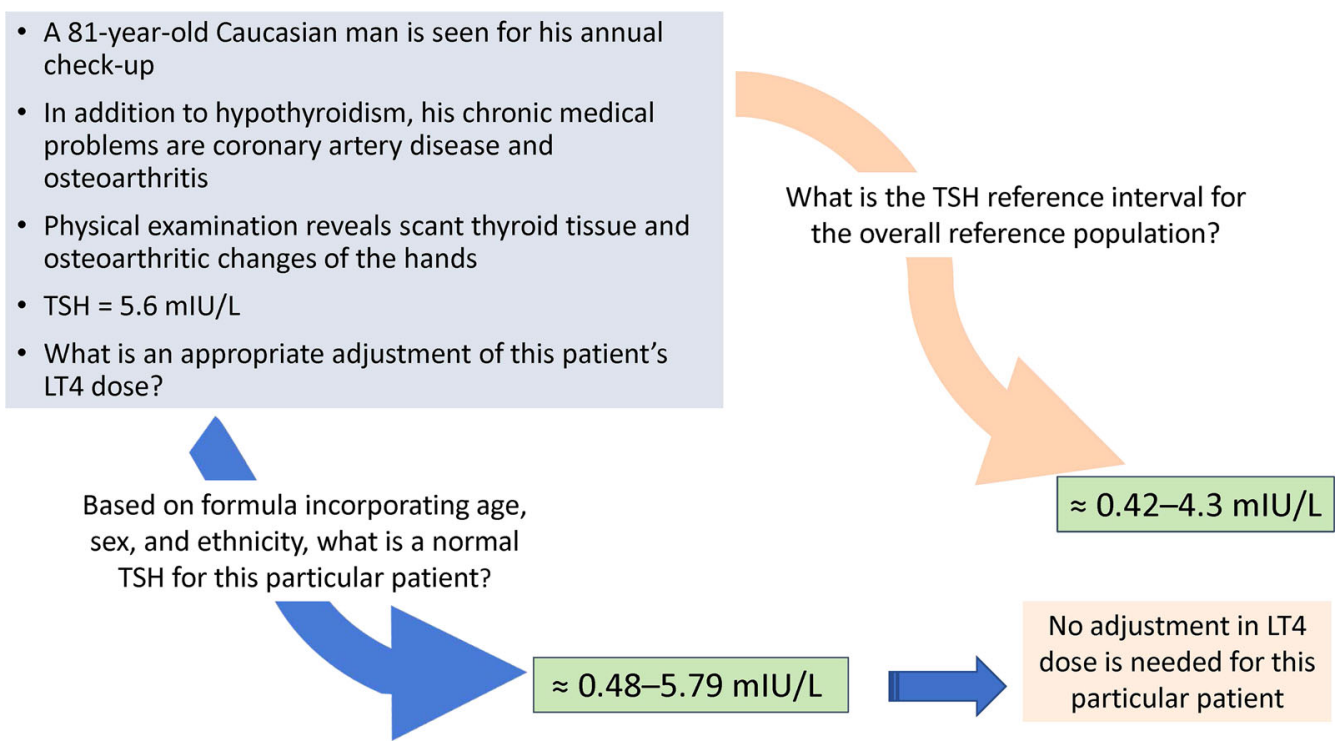

Fig. 3 Example of application of age-adjusted thyroid-stimulating hormone reference ranges to patient treatment. LT4 levothyroxine, TSH thyroid-stimulating hormone

\section{LEVOTHYROXINE DOSE ADJUSTMENTS ASSOCIATED WITH CONCOMITANT MEDICAL CONDITIONS AND MEDICATIONS}

Levothyroxine is best absorbed when the stomach environment is acidic and is absorbed mainly in the jejunum and ileum [51]. It is primarily metabolised by de-iodination, but also is metabolised by conjugation, decarboxylation, and deamination. Based on this route into and out of the body, there are many medical conditions and medications that can impact these steps and alter the levothyroxine dose requirement. Two studies illustrate the combined impact of medical conditions and medications [52, 53]. A study of a pharmaceutical company-sponsored database identified gastrointestinal conditions and medications such as iron, calcium, and acid-lowering therapies as being associated with difficulty controlling hypothyroid symptoms and frequent changes in levothyroxine doses [52]. Gastrointestinal conditions and interfering medications were also identified as being associated with the finding of patients requiring higher than predicted doses of levothyroxine in an audit of patients being treated by physicians in the national health system in Scotland [53].

\section{Medical Conditions}

Generally speaking, although other chronic medical conditions such as cardiac disease, hepatic disease, osteoporosis, or diabetes do not directly impact levothyroxine dose requirements, some individuals with these conditions may be elderly or frail and thus extra caution may need to be exercised to avoid under- or over-dosing. One specific medical condition in which levothyroxine doses that lower serum TSH may be intentionally employed is differentiated thyroid cancer [54]. If TSH suppression is the goal in patients with intermediate- or high-risk thyroid cancer, higher doses up to $2.2 \mu \mathrm{g} / \mathrm{kg}$ body weight may be needed [8]. However, TSH suppression is not necessary in low-risk patients or in patients who no longer have a substantial risk of thyroid cancer recurrence (Fig. 4). Patients with hypothyroidism who are hospitalised with critical illness may require higher doses of levothyroxine while hospitalised [55], possibly because of such factors as use of proton pump inhibitors or decreased absorption associated with enteral 


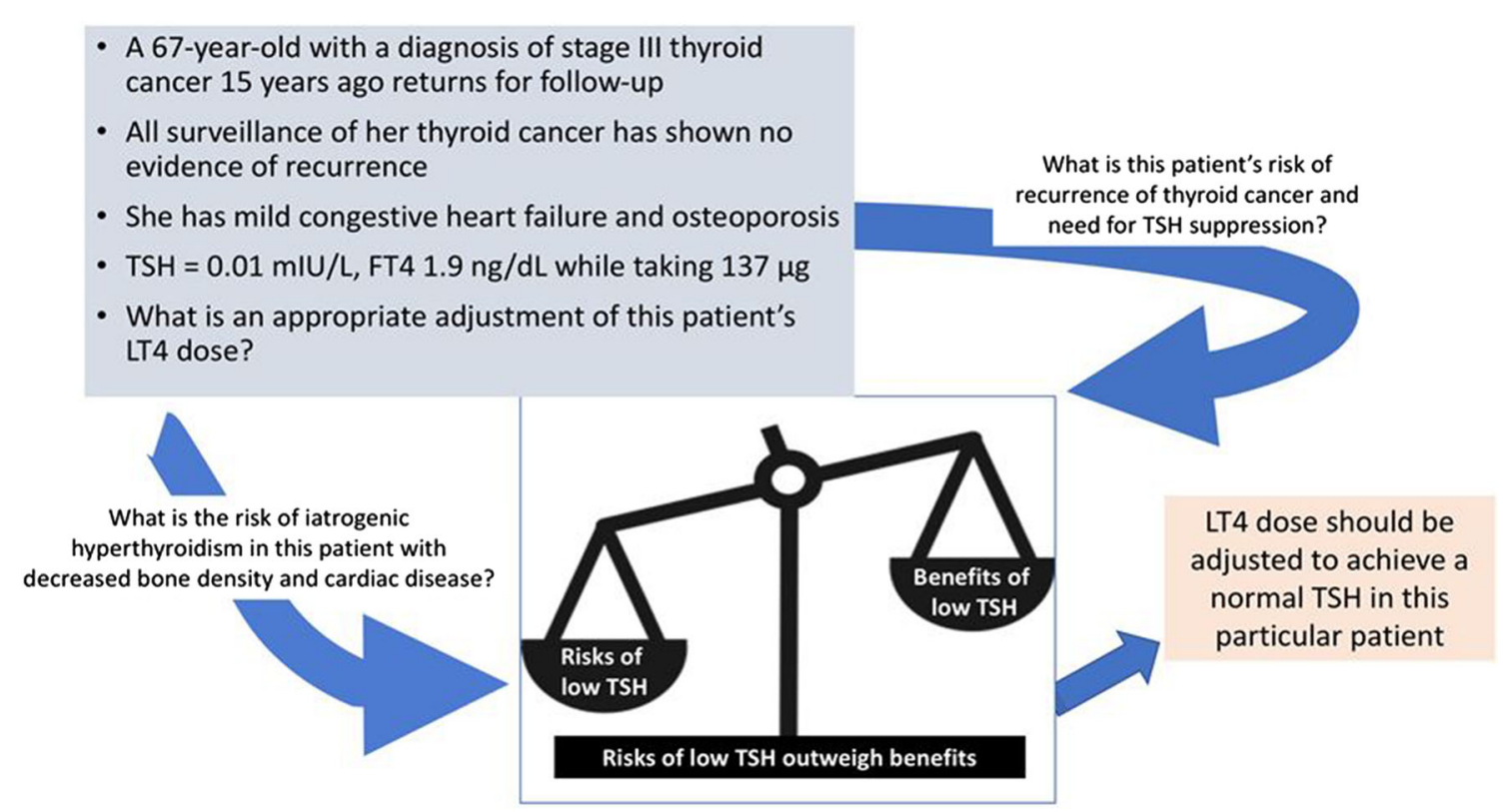

Fig. 4 Example of balancing risks and benefits in order to choose a target thyroid-stimulating hormone value for a patient. LT4 levothyroxine, TSH thyroid-stimulating hormone

feeding. Decreased absorption caused by enteral feeding may be circumvented by temporarily holding tube feeds prior to levothyroxine administration or using liquid preparations of levothyroxine [56]. There may also be failure to prescribe levothyroxine appropriately in the hospital setting [57].

A variety of gastrointestinal conditions may be associated with decreased levothyroxine absorption and higher serum TSH levels when the condition is untreated compared with when the condition is treated [51]. These conditions include gastritis, coeliac disease, and lactose intolerance. Helicobacter pylori-associated gastritis is associated with increased levothyroxine requirement, with the increased requirement resolving with treatment of the gastritis $[58,59]$. Similarly, untreated coeliac disease is associated with a high levothyroxine requirement that is remediated by dietary treatment of the coeliac disease $[60,61]$. The same pattern has been demonstrated with lactose intolerance [62]. While each of these conditions remains in the untreated state, it appears that levothyroxine absorption is better when liquid levothyroxine is utilised for patient therapy [63-65]. Nephrotic syndrome is another medical condition associated with a need for an increased dose of levothyroxine, presumably due to urinary losses of thyroid hormones, accompanying the urinary losses of thyroxine-binding globulin [66].

\section{Medications, Supplements, and Food}

Medications may alter a patient's requirement for levothyroxine through a variety of mechanisms (Table 1). These mechanisms include altered levothyroxine absorption, altered thyroid hormone synthesis or release (theoretically relevant for those who still have some residual thyroid function), altered transport of levothyroxine, altered metabolism of levothyroxine, and altered TSH secretion. A partial list of some of the implicated drugs is shown in Table 1 , and more complete discussion of these drugs can be found in several review articles [8, 51, 67-69]. In most cases, the net result is a need for an increased levothyroxine dose. A classic example of a medication that causes an increased requirement for levothyroxine is oestrogen therapy [70, 71], which is associated with increased levels of thyroxine-binding globulin. Tyrosine kinase inhibitors can have multiple effects, including causing an increased need for levothyroxine via increasing the metabolism of levothyroxine (Fig. 5) [68, 72]. 
Table 1 Drugs affecting levothyroxine requirement and the mechanism of altered requirement

\begin{tabular}{|c|c|c|c|c|c|c|}
\hline Drug & $\begin{array}{l}\text { Altered LT4 } \\
\text { requirement }\end{array}$ & $\begin{array}{l}\text { Altered LT4 } \\
\text { absorption }\end{array}$ & $\begin{array}{l}\text { Altered TH } \\
\text { synthesis or release }\end{array}$ & $\begin{array}{l}\text { Altered } \\
\text { transport }\end{array}$ & $\begin{array}{l}\text { Altered } \\
\text { metabolism }\end{array}$ & $\begin{array}{l}\text { Altered TSH } \\
\text { secretion }\end{array}$ \\
\hline Oestrogen & $\uparrow$ & & & $x$ & & \\
\hline Androgens & $\downarrow$ & & & $x$ & & \\
\hline Glucocorticoids & $\downarrow$ & & & $x$ & & $x$ \\
\hline Phenobarbital & $\uparrow$ & & & & $x$ & \\
\hline TKI & $\uparrow \downarrow$ & & & & $x$ & \\
\hline Rifampin & $\uparrow$ & & & & $x$ & \\
\hline Sertraline & $\uparrow$ & & & & $x$ & \\
\hline Amiodarone & $\uparrow \downarrow$ & & $x$ & & $x$ & \\
\hline Iodine & $\uparrow \downarrow$ & & $x$ & & & \\
\hline Lithium & $\uparrow \downarrow$ & & $x$ & & & \\
\hline $\begin{array}{l}\text { Dopamine, } \\
\text { dobutamine }\end{array}$ & & & & & & $x$ \\
\hline Bexarotene & $\uparrow$ & & & & & $x$ \\
\hline $\begin{array}{l}\text { Calcium } \\
\text { carbonate }\end{array}$ & $\uparrow$ & $x$ & & & & \\
\hline PPI & $\uparrow$ & $x$ & & & & \\
\hline $\begin{array}{l}\text { Ferrous } \\
\text { sulphate }\end{array}$ & $\uparrow$ & $\times$ & & & & \\
\hline Cholestyramine & $\uparrow$ & $\times$ & & & & \\
\hline $\begin{array}{c}\text { Phosphate } \\
\text { binders }\end{array}$ & $\uparrow$ & $x$ & & & & \\
\hline
\end{tabular}

LT4 levothyroxine, PPI proton pump inhibitors, TH thyroid hormone, THS thyroid-stimulating hormone, TKI tyrosine kinase inhibitors

If levothyroxine is ingested along with food, its absorption can be impaired [15, 51]. Soycontaining foods are an example of a substance that can decrease absorption (Fig. 6) [73]. Calcium supplements $[74,75]$ and iron $[76,77]$ also reduce absorption and thereby increase the levothyroxine dose requirement or increase serum TSH $[52,53]$. Vitamin C stands alone as an example of a supplement that may actually decrease the requirement for levothyroxine by enhancing its absorption, at least in patients with gastritis [78].

\section{CONTROVERSIES ABOUT TREATMENT OTHER THAN LEVOTHYROXINE}

No consistently strong evidence has been found for the superiority of any alternative preparation (e.g., levothyroxine/liothyronine combination therapy, thyroid extract therapy, or others) over monotherapy with levothyroxine in improving health outcomes [8]. Trials of such therapy show mixed results regarding patient preference for combination therapy or other alternative therapies [8]. On an anecdotal basis 
- A 65 year old man with hypothyroidism is started on sorafenib for his renal cell carcinoma

- He presents with new onset symptoms of hypothyroidism, despite taking his $137 \mu \mathrm{g}$ dose of LT4 regularly

- Biochemical parameters confirm hypothyroidism with a TSH of $55 \mathrm{mIU} / \mathrm{L}$, compared with a prior TSH of $2.3 \mathrm{mIU} / \mathrm{L}$

-What accounts for this?

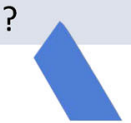

Increased TSH and decreased T3/rT3 ratio documented in patients after initiation of sorafenib

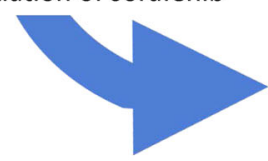

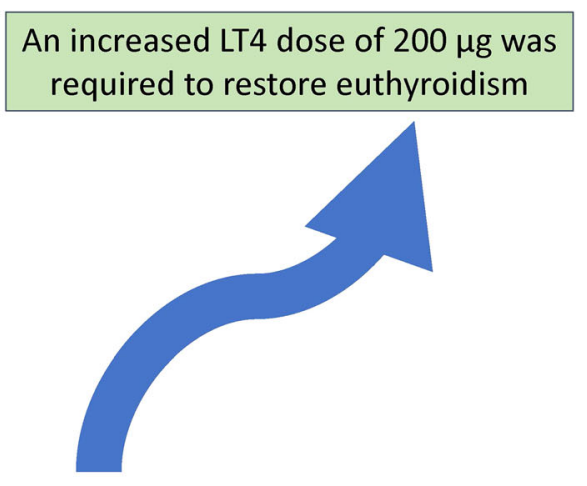

Tyrosine kinase inhibitors, including sorafenib, accelerate conversion of T3 to rT3, thus increasing LT4 requirement

Fig. 5 Example of how to adjust levothyroxine dose in patients receiving concomitant medications. LT4 levothyroxine, $r T 3$ reverse triiodothyronine, T3 triiodothyronine, TSH thyroid-stimulating hormone

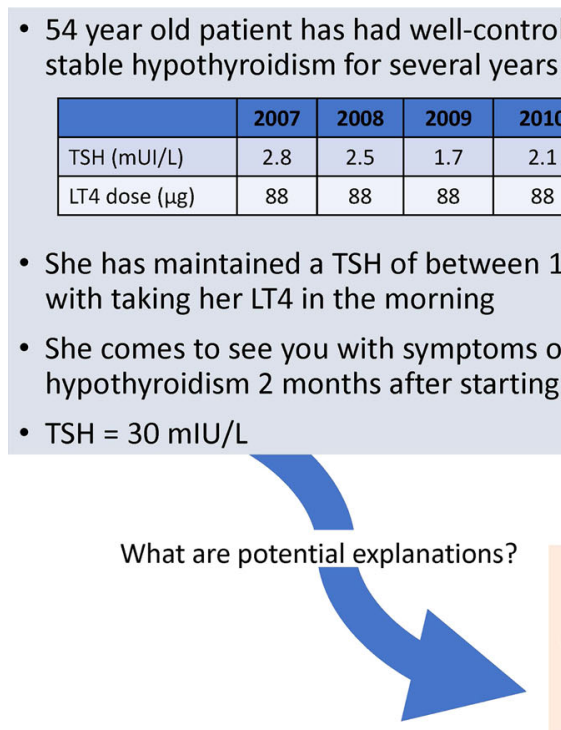

Factors decreasing levothyroxine absorption:

- Food, beverages

- Gastrointestinal conditions

- Medications

Fig. 6 Example of how to adjust levothyroxine dose in patients consuming foods that may impair absorption. LT4 levothyroxine, TSH thyroid-stimulating hormone

some patients may perceive benefit from combination therapy, whereas others may not (Fig. 7). However, in some patients, levothyroxine replacement is associated with significant impairment in psychological well-being [79], including compared with euthyroid controls [80], and as such there is interest in studies comparing combined levothyroxine/liothyronine with levothyroxine monotherapy. One example of a study addressing this controversy is a randomised, double-blind study that was carried out comparing treatment with levothyroxine/liothyronine at a ratio of $5: 1$ or 10:1 with levothyroxine monotherapy in 141 patients 
- A 25 year old woman with hypothyroidism notes persistent symptoms of hypothyroidism

- She takes her $88 \mu \mathrm{g}$ LT4 regularly

- Biochemical evaluation shows TSH $1.7 \mathrm{mIU} / \mathrm{L}$, FT4 $1.5 \mathrm{ng} / \mathrm{dL}$, T3 $70 \mathrm{ng} / \mathrm{dL}$

- She states that her mother is being treated with LT3 and is doing well and she requests this therapy also

- What are potential outcomes and explanations if such therapy is initiated?

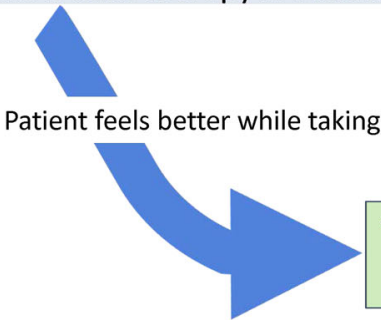

- Patient's hypothyroidism may be more effectively treated with LT3 because of genetic underpinning and/or normalization of T3 levels - Placebo effect

Fig. 7 Illustration of potential responses of a patient to a trial of combination therapy with levothyroxine and liothyronine. FT4 free thyroxine, LT3 liothyronine, LT4 levothyroxine, TSH thyroid-stimulating hormone, T3 triiodothyronine

(18-70 years old) with primary autoimmune hypothyroidism [81]. It was observed that more patients on combination therapy displayed elevated triiodothyronine levels. While patients showed a preference for the combined treatment over levothyroxine therapy (the primary study outcome), the positive changes in mood, well-being, fatigue, and neurocognitive functions reported (secondary outcomes) occurred in all treatment groups and could not entirely account for the fact that the primary outcome strongly supported combined therapy. Meanwhile, a reduction in body weight, though not in serum TSH, correlated with greater satisfaction with the study medication [81]. Finally, among those patients who preferred the combined levothyroxine/liothyronine therapy, 44\% had serum TSH levels $<0.11 \mathrm{mU} / \mathrm{l}$.

It has been hypothesised that the Thr92Ala D2 polymorphism may influence the enzymatic activity of deiodinase II (DIO2), thereby predicting a positive response to combined levothyroxine/liothyronine therapy. In a study with 12,625 participants from the LifeLines cohort study using available genome-wide genetic data, the effects of the Thr92Ala polymorphism (rs225014) were evaluated in the general population and in 364 individuals undergoing levothyroxine replacement therapy mainly due to primary hypothyroidism [82]. In both groups, the D2-Thr92Ala polymorphism was not associated with differences in TSH, free thyroxine and free triiodothyronine, presence of metabolic syndrome, other comorbidities, HRQoL, and cognitive functioning [82]. However, new findings in rodents indicate that carriers of the Thr92Ala-D2 polymorphism may exhibit lower D2 catalytic activity and diminished thyroid hormone signalling resulting in localised/systemic hypothyroidism [83]. These findings, if replicated in humans, may widen the opportunity for a more personalised approach to the treatment of hypothyroidism [84].

A recent survey, which queried the treatment of hypothyroidism by presenting 13 theoretical patients and offering 6 therapeutic options, was emailed to the members of the American Thyroid Association (ATA) prior to a satellite symposium of their Spring Meeting and also before the annual Endocrine Society and ATA Meetings. A multivariate analysis of the results revealed that physician characteristics may affect prescription patterns, with residents of North America, for example, being more inclined to prescribe therapies incorporating 
liothyronine than their colleagues in Europe $[85,86]$. However, the study was not designed to investigate whether this was due to physician-patient interaction, specific education following the meetings, the influence of pharmaceutical companies, or media exposure, or a combination of these. The fact that physicians indicate their willingness to prescribe a liothyronine-containing treatment may indicate a need for more research to understand patient preferences, which may sway physicians' choices when considering prescribing liothyronine combined with levothyroxine, and the risks and benefits of such therapy.

\section{CONCLUSION}

This review highlights the complexity of maintaining biochemical and clinical euthyroidism in patients undergoing treatment with levothyroxine. Challenges include the physiological changes that occur as adult patients progress through the stages of life as well as the alterations in levothyroxine needs that may be associated with concomitant medical conditions and medications. Optimal treatment of hypothyroidism requires a partnership between patient and physician. The physician is tasked with vigilant appraisal of the patient's status based on a thorough clinical and laboratory assessment and appropriate adjustment of their levothyroxine therapy. The patient in turn is tasked with medication adherence and reporting of symptomatology and any changes in their medical situation. The goal is consistent maintenance of euthyroidism, without the patient experiencing the adverse events and negative health consequences of under- or overtreatment.

\section{ACKNOWLEDGEMENTS}

This supplement has been sponsored by Merck.

Funding. Sponsorship for this manuscript, the Rapid Service Fees, and the Open Access fee were all funded by Merck.
Medical Writing, Editorial, and Other Assistance. We would like to thank Simone Tait of Springer Healthcare who edited this manuscript before submission. This medical writing assistance was funded by Merck.

Authorship. All named authors meet the International Committee of Medical Journal Editors (ICMJE) criteria for authorship for this article, take responsibility for the integrity of the work as a whole, and have given their approval for this version to be published.

Disclosures. Leonidas H. Duntas and Jacqueline Jonklaas have nothing to disclose related to this work. This research did not receive any specific grant from any funding agency in the public, commercial, or not-for profit sector.

Compliance with Ethics Guidelines. This article is based on previously conducted studies and does not contain any studies with animals performed by any of the authors. Some of studies cited include analyses, or studies with human participants, performed by the authors and completed prior to the initiation of this manuscript.

Open Access. This article is distributed under the terms of the Creative Commons Attribution-NonCommercial 4.0 International License (http://creativecommons.org/licenses/ by-nc/4.0/), which permits any noncommercial use, distribution, and reproduction in any medium, provided you give appropriate credit to the original author(s) and the source, provide a link to the Creative Commons license, and indicate if changes were made.

\section{REFERENCES}

1. Kendall EC. The isolation in crystalline form of the compound containing iodin, which occurs in the thyroid: its chemical nature and physiologic activity. JAMA. 1915;LXIV(25):2042-3.

2. Harington CR, Barger G. Chemistry of thyroxine: constitution and synthesis of thyroxine. Biochem J. 1927;21(1):169-83. 
3. Chalmers J, Dickson G, Elks J, Hems BA. The synthesis of thyroxine and related substances. Part V. A synthesis of L-thyroxine from L-tyrosine. J Chem Soc. 1949. https://doi.org/10.1039/JR9490003424

4. Slater S. The discovery of thyroid replacement therapy. Part 2: the critical 19th century. J R Soc Med. 2011;104(2):59-63.

5. Slater S. The discovery of thyroid replacement therapy. Part 1: in the beginning. J R Soc Med. 2011;104(1):15-8.

6. Bianco AC, Salvatore D, Gereben B, Berry MJ, Larsen PR. Biochemistry, cellular and molecular biology, and physiological roles of the iodothyronine selenodeiodinases. Endocr Rev. 2002;23(1):38-89.

7. Chaker L, Bianco AC, Jonklaas J, Peeters RP. Hypothyroidism. Lancet. 2017;390(10101):1550-62.

8. Jonklaas J, Bianco AC, Bauer AJ, et al. Guidelines for the treatment of hypothyroidism: prepared by the American Thyroid Association task force on thyroid hormone replacement. Thyroid. 2014;24(12):1670751.

9. Kabadi UM, Kabadi MM. Serum thyrotropin in primary hypothyroidism: a reliable and accurate predictor of optimal daily levothyroxine dose. Endocr Pract. 2001;7(1):16-8.

10. Elfenbein DM, Schaefer S, Shumway C, Chen H, Sippel RS, Schneider DF. Prospective intervention of a novel levothyroxine dosing protocol based on body mass index after thyroidectomy. J Am Coll Surg. 2016;222(1):83-8.

11. Ojomo KA, Schneider DF, Reiher AE, et al. Using body mass index to predict optimal thyroid dosing after thyroidectomy. J Am Coll Surg. 2013;216(3): 454-60.

12. Jin J, Allemang MT, McHenry CR. Levothyroxine replacement dosage determination after thyroidectomy. Am J Surg. 2013;205(3):360-3.

13. Santini F, Pinchera A, Marsili A, et al. Lean body mass is a major determinant of levothyroxine dosage in the treatment of thyroid diseases. J Clin Endocrinol Metab. 2005;90(1):124-7.

14. Jonklaas J. Update on the treatment of hypothyroidism. Curr Opin Oncol. 2016;28(1):18-25.

15. Bach-Huynh TG, Nayak B, Loh J, Soldin S, Jonklaas J. Timing of levothyroxine administration affects serum thyrotropin concentration. J Clin Endocrinol Metab. 2009;94(10):3905-12.

16. Pecina J, Garrison GM, Bernard ME. Levothyroxine dosage is associated with stability of thyroid- stimulating hormone values. Am J Med. 2014; 127(3):240-5.

17. Ashrafpour R, Ayati N, Sadeghi R, et al. Comparison of treatment response achieved by tablet splitting versus whole tablet administration of levothyroxine in patients with thyroid cancer. Asia Ocean J Nucl Med Biol. 2018;6(2):108-12.

18. Hepp Z, Lage MJ, Espaillat R, Gossain VV. The association between adherence to levothyroxine and economic and clinical outcomes in patients with hypothyroidism in the US. J Med Econ. 2018;21(9):912-9.

19. Walker JN, Shillo P, Ibbotson V, et al. A thyroxine absorption test followed by weekly thyroxine administration: a method to assess non-adherence to treatment. Eur J Endocrinol. 2013;168(6):913-7.

20. Grebe SK, Cooke RR, Ford HC, et al. Treatment of hypothyroidism with once weekly thyroxine. J Clin Endocrinol Metab. 1997;82(3):870-5.

21. Jauk B, Mikosch P, Gallowitsch HJ, et al. Unusual malabsorption of levothyroxine. Thyroid. 2000;10(1):93-5.

22. Groener JB, Lehnhoff D, Piel D, Nawroth PP, Schanz J, Rudofsky G. Subcutaneous application of levothyroxine as successful treatment option in a patient with malabsorption. Am J Case Rep. 2013;14:48-51.

23. Taylor PN, Tabasum A, Sanki G, et al. Weekly intramuscular injection of levothyroxine following myxoedema: a practical solution to an old crisis. Case Rep Endocrinol. 2015;2015:169194.

24. Ernst FR, Barr P, Elmor R, et al. The economic impact of levothyroxine dose adjustments: the CONTROL HE study. Clin Drug Investig. 2017;37(1):71-83.

25. Livadas S, Bothou C, Androulakis I, Boniakos A, Angelopoulos N, Duntas L. Levothyroxine replacement therapy and overuse: a timely diagnostic approach. Thyroid. 2018;28:1580-6. https://doi. org/10.1089/thy.2018.0014

26. Younis IR, Ahmed MA, Burman KD, Soldin OP, Jonklaas J. Stable isotope pharmacokinetic studies provide insight into effects of age, sex, and weight on levothyroxine metabolism. Thyroid. 2018;28(1): 41-9.

27. Shrestha RT, Malabanan A, Haugen BR, Levy EG, Hennessey JV. Adverse event reporting in patients treated with thyroid hormone extract. Endocr Pract. 2017;23(5):566-75. 
28. Balsa AM, Ferreira AR, Alves M, Guimarães J. Takotsubo cardiomyopathy associated with levothyroxine over-replacement. Eur Endocrinol. 2017;13(1):30-2.

29. Kim MK, Yun KJ, Kim MH, et al. The effects of thyrotropin-suppressing therapy on bone metabolism in patients with well-differentiated thyroid carcinoma. Bone. 2015;71:101-5.

30. Vigário Pdos S, Vaisman F, Coeli CM, et al. Inadequate levothyroxine replacement for primary hypothyroidism is associated with poor health-related quality of life-a Brazilian multicentre study. Endocrine. 2013;44(2):434-40.

31. U.S. Food and Drug Administration. FDA acts to ensure thyroid drugs don't lose potency before expiration date. 3 October 2007. http://www.fda. gov/drugs/drugsafety/postmarketdrugsafety informationforpatientsandproviders/ucm 161259. htm. Accessed 3 May 2019.

32. Blakesley V, Awni W, Locke C, Ludden T, Granneman GR, Braverman LE. Are bioequivalence studies of levothyroxine sodium formulations in euthyroid volunteers reliable? Thyroid. 2004;14(3):191-200.

33. Wartofsky L. Levothyroxine: therapeutic use and regulatory issues related to bioequivalence. Expert Opin Pharmacother. 2002;3(6):727-32.

34. Alexander EK, Pearce EN, Brent GA, et al. 2017 guidelines of the american thyroid association for the diagnosis and management of thyroid disease during pregnancy and the postpartum. Thyroid. 2017;27(3):315-89.

35. Loh JA, Wartofsky L, Jonklaas J, Burman KD. The magnitude of increased levothyroxine requirements in hypothyroid pregnant women depends upon the etiology of the hypothyroidism. Thyroid. 2009;19(3):269-75.

36. Abalovich M, Alcaraz G, Kleiman-Rubinsztein J, et al. The relationship of preconception thyrotropin levels to requirements for increasing the levothyroxine dose during pregnancy in women with primary hypothyroidism. Thyroid. 2010;20(10): 1175-8.

37. Yassa L, Marqusee E, Fawcett R, Alexander EK. Thyroid hormone early adjustment in pregnancy (the THERAPY) trial. J Clin Endocrinol Metab. 2010;95(7):3234-41.

38. Sullivan SD, Downs E, Popoveniuc G, Zeymo A, Jonklaas J, Burman KD. Randomized trial comparing two algorithms for levothyroxine dose adjustment in pregnant women with primary hypothyroidism. J Clin Endocrinol Metab. 2017;102(9):3499-507.
39. Busnelli A, Vannucchi G, Paffoni A, et al. Levothyroxine dose adjustment in hypothyroid women achieving pregnancy through IVF. Eur J Endocrinol. 2015;173(4):417-24.

40. Devdhar M, Drooger R, Pehlivanova M, Singh G, Jonklaas J. Levothyroxine replacement doses are affected by gender and weight, but not age. Thyroid. 2011;21(8):821-7.

41. Michalaki MA, Gkotsina MI, Mamali I, et al. Impaired pharmacokinetics of levothyroxine in severely obese volunteers. Thyroid. 2011;21(5): 477-81.

42. Gadiraju S, Lee CJ, Cooper DS. Levothyroxine dosing following bariatric surgery. Obes Surg. 2016;26(10):2538-42.

43. Padwal R, Brocks D, Sharma AM. A systematic review of drug absorption following bariatric surgery and its theoretical implications. Obes Rev. 2010;11(1):41-50.

44. Fallahi P, Ferrari SM, Camastra S, et al. TSH normalization in bariatric surgery patients after the switch from L-thyroxine in tablet to an oral liquid formulation. Obes Surg. 2017;27(1):78-82.

45. Jonklaas J. Sex and age differences in levothyroxine dosage requirement. Endocr Pract. 2010;16(1):71-9.

46. Baehr KM, Lyden E, Treude K, Erickson J, Goldner $\mathrm{W}$. Levothyroxine dose following thyroidectomy is affected by more than just body weight. Laryngoscope. $2012 ; 122(4): 834-8$.

47. Tahboub R, Arafah BM. Sex steroids and the thyroid. Best Pract Res Clin Endocrinol Metab. 2009;23(6):769-80.

48. Sawin CT, Herman T, Molitch ME, London MH, Kramer SM. Aging and the thyroid. Decreased requirement for thyroid hormone in older hypothyroid patients. Am J Med. 1983;75(2):206-9.

49. Del Duca SC, Santaguida MG, Brusca N, et al. Individually-tailored thyroxine requirement in the same patients before and after thyroidectomy: a longitudinal study. Eur J Endocrinol. 2015; 173(3):351-7.

50. Boucai L, Hollowell JG, Surks MI. An approach for development of age-, gender-, and ethnicity-specific thyrotropin reference limits. Thyroid. 2011;21(1):5-11.

51. Virili C, Antonelli A, Santaguida MG, Benvenga S, Centanni M. Gastrointestinal malabsorption of thyroxine. Endocr Rev. 2019;40(1):118-36. 
52. McMillan M, Rotenberg KS, Vora K, et al. Comorbidities, concomitant medications, and diet as factors affecting levothyroxine therapy: results of the CONTROL surveillance project. Drugs $\mathrm{R} D$. 2016;16(1):53-68.

53. Robertson HM, Narayanaswamy AK, Pereira O, et al. Factors contributing to high levothyroxine doses in primary hypothyroidism: an interventional audit of a large community database. Thyroid. 2014;24(12): 1765-71.

54. Carhill AA, Litofsky DR, Ross DS, et al. Long-term outcomes following therapy in differentiated thyroid carcinoma: NTCTCS Registry Analysis 1987-2012. J Clin Endocrinol Metab. 2015;100(9): 3270-9.

55. Imberti R, Ferrari M, Albertini R, Rizzo V, Tinelli C, Iotti GA. Increased levothyroxine requirements in critically ill patients with hypothyroidism. Minerva Anestesiol. 2010;76(7):500-3.

56. Pirola I, Daffini L, Gandossi E, et al. Comparison between liquid and tablet levothyroxine formulations in patients treated through enteral feeding tube. J Endocrinol Investig. 2014;37(6):583-7.

57. Barrett NA, Jones A, Whiteley C, Yassin S, McKenzie CA. Management of long-term hypothyroidism: a potential marker of quality of medicines reconciliation in the intensive care unit. Int J Pharm Pract. 2012;20(5):303-6.

58. Centanni M, Gargano L, Canettieri G, et al. Thyroxine in goiter, Helicobacter pylori infection, and chronic gastritis. N Engl J Med. 2006;354(17): 1787-95.

59. Bugdaci MS, Zuhur SS, Sokmen M, Toksoy B, Bayraktar B, Altuntas Y. The role of Helicobacter pylori in patients with hypothyroidism in whom could not be achieved normal thyrotropin levels despite treatment with high doses of thyroxine. Helicobacter. 2011;16(2):124-30.

60. Collins D, Wilcox R, Nathan M, Zubarik R. Celiac disease and hypothyroidism. Am J Med. 2012;125(3):278-82.

61. Virili C, Bassotti G, Santaguida MG, et al. Atypical celiac disease as cause of increased need for thyroxine: a systematic study. J Clin Endocrinol Metab. 2012;97(3):E419-22.

62. Cellini M, Santaguida MG, Gatto I, et al. Systematic appraisal of lactose intolerance as cause of increased need for oral thyroxine. J Clin Endocrinol Metab. 2014;99(8):E1454-8.

63. Ribichini D, Fiorini G, Repaci A, et al. Tablet and oral liquid L-thyroxine formulation in the treatment of naive hypothyroid patients with Helicobacter pylori infection. Endocrine. 2017;57(3): 394-401.

64. Fallahi P, Ferrari SM, Marchi S, De Bortoli N, Ruffilli I, Antonelli A. Patients with lactose intolerance absorb liquid levothyroxine better than tablet levothyroxine. Endocrine. 2017;57(1):175-8.

65. Santaguida MG, Virili C, Del Duca SC, et al. Thyroxine softgel capsule in patients with gastric-related T4 malabsorption. Endocrine. 2015;49(1): 51-7.

66. Karethimmaiah H, Sarathi V. Nephrotic syndrome increases the need for levothyroxine replacement in patients with hypothyroidism. J Clin Diagn Res. 2016;10(12):OC10-2.

67. Liwanpo L, Hershman JM. Conditions and drugs interfering with thyroxine absorption. Best Pract Res Clin Endocrinol Metab. 2009;23(6):781-92.

68. Torino F, Barnabei A, Paragliola R, Baldelli R, Appetecchia M, Corsello SM. Thyroid dysfunction as an unintended side effect of anticancer drugs. Thyroid. 2013;23(11):1345-66.

69. Surks MI, Sievert R. Drugs and thyroid function. N Engl J Med. 1995;333(25):1688-94.

70. Irving SA, Vadiveloo T, Leese GP. Drugs that interact with levothyroxine: an observational study from the Thyroid Epidemiology, Audit and Research Study (TEARS). Clin Endocrinol (Oxf). 2015;82(1):136-41.

71. Arafah BM. Increased need for thyroxine in women with hypothyroidism during estrogen therapy. N Engl J Med. 2001;344(23):1743-9.

72. Abdulrahman RM, Verloop $\mathrm{H}$, Hoftijzer $\mathrm{H}$, et al. Sorafenib-induced hypothyroidism is associated with increased type 3 deiodination. J Clin Endocrinol Metab. 2010;95(8):3758-62.

73. Messina M, Redmond G. Effects of soy protein and soybean isoflavones on thyroid function in healthy adults and hypothyroid patients: a review of the relevant literature. Thyroid. 2006;16(3):249-58.

74. Singh N, Weisler SL, Hershman JM. The acute effect of calcium carbonate on the intestinal absorption of levothyroxine. Thyroid. 2001;11(10):967-71.

75. Zamfirescu I, Carlson HE. Absorption of levothyroxine when coadministered with various calcium formulations. Thyroid. 2011;21(5):483-6.

76. Shakir KM, Chute JP, Aprill BS, Lazarus AA. Ferrous sulfate-induced increase in requirement for 
thyroxine in a patient with primary hypothyroidism. South Med J. 1997;90(6):637-9.

77. Campbell NR, Hasinoff BB, Stalts H, Rao B, Wong NC. Ferrous sulfate reduces thyroxine efficacy in patients with hypothyroidism. Ann Intern Med. 1992;117(12):1010-3.

78. Jubiz W, Ramirez M. Effect of vitamin C on the absorption of levothyroxine in patients with hypothyroidism and gastritis. J Clin Endocrinol Metab. 2014;99(6):E1031-4.

79. Peterson SJ, Cappola AR, Castro MR, et al. An online survey of hypothyroid patients demonstrates prominent dissatisfaction. Thyroid. 2018;28(6): 707-21.

80. Saravanan P, Chau WF, Roberts N, Vedhara K, Greenwood R, Dayan CM. Psychological well-being in patients on 'adequate' doses of L-thyroxine: results of a large, controlled community-based questionnaire study. Clin Endocrinol (Oxf). 2002;57(5):577-85.

81. Appelhof BC, Fliers E, Wekking EM, et al. Combined therapy with levothyroxine and liothyronine in two ratios, compared with levothyroxine monotherapy in primary hypothyroidism: a double-blind, randomized, controlled clinical trial. J Clin Endocrinol Metab. 2005;90(5):2666-74.

82. Wouters HJ, van Loon HC, van der Klauw MM, et al. No effect of the Thr92Ala polymorphism of deiodinase- 2 on thyroid hormone parameters, health-related quality of life, and cognitive functioning in a large population-based cohort study. Thyroid. 2017;27(2):147-55.

83. Jo S, Fonseca TL, Bocco B, et al. Type 2 deiodinase polymorphism causes ER stress and hypothyroidism in the brain. J Clin Investig. 2019;129(1):230-45.

84. Bianco AC, Kim BS. Pathophysiological relevance of deiodinase polymorphism. Curr Opin Endocrinol Diabetes Obes. 2018;25(5):341-6.

85. Jonklaas J, Tefera E, Shara N. Short-term time trends in prescribing therapy for hypothyroidism: results of a survey of American Thyroid Association members. Front Endocrinol (Lausanne). 2019;10:31.

86. Jonklaas J, Tefera E, Shara N. Prescribing therapy for hypothyroidism: influence of physician characteristics. Thyroid. 2019;29(1):44-52. 